\title{
Commentary
}

\section{On the Potential Role for Interventional Pain Management in Palliative Care}

From: ${ }^{1,2}$ Georgetown University Medical Center, Washington, DC, 3Veterans Administration Hospital, Baltimore, MD Dr. Giordano ${ }^{1}$ is Scholar in Residence, Center for Clinical Bioethics, Associate Professor Division of Palliative Medicine, Georgetown University Medical Center, Washington, DC. Dr.

Gomez $^{2}$ is Adjunct Lecturer, Center for Clinical Bioethics Georgetown University Medical Center, Washington, DC. Dr. Harrison ${ }^{3}$ is with the Veterans Administration Hospital, Palliative Care Program, Baltimore, MD.

Address Correspondence: James Giordano, PhD

Center for Clinical Bioethics and Division of Palliative Medicine Georgetown University Medical Center 4000 Reservoir Rd, Bldg. D Washington, DC 20057 Email: jgiordano@neurobioethics.org

Funding: Samueli Institute, Center for Brain, Mind, and Healing. Conflict of Interest: None.

Manuscript received on: 04/01/2007 Revisions accepted: 04/11/2007 Accepted for publication on: $04 / 24 / 2007$

Free Full manuscript: www.painphysicianjournal.com

\author{
The Relation and Realities of Pain, Suffering, and \\ Medicine
}<smiles>C1CCCCCCCCCC1</smiles>
he success of technological advancements within science and medicine has enabled both a considerable curative potential, and the prolongation of the lifespan of those patients with incurable disease(s). Such success has, as an artifact, fostered the chronicity of disease and illness. This has accentuated the realities of 1) pain and suffering - as consequences of longitudinal disease and illness, and 2) medicine's need to develop those dimensions of practice that seek to heal what cannot be cured. In part, the practices of pain medicine and palliative care have arisen from this need (1). The former to address pain specifically, and the latter to render somewhat more broadly construed healing care to reduce suffering.

The reciprocal relationship of pain and suffering, while not uniformly direct, is nevertheless undeniable. Pain can evoke suffering, and while all suffering is not produced by (physical) pain, if we consider a more encompassing construct of pain - as a phenomenon of consciousness - then suffering can, and frequently does evoke pain (2). The direct relation of physical pain to suffering is best upheld in situations of severe acute and intractable, durable pain. The suffering incurred involves not only the noxiousness of the pain, per se, but makes the patient increasingly restricted from experiencing the world beyond pain, progressively dis-attuned to the lived body, and ever more limited to interact with others (3). In other words, pain and suffering incur considerable loss - of time, experience, and sense of self.

For the patient with longitudinal chronic illness (including chronic, intractable pain), such suffering creates dim prospects for the remainder of life, and such nihilism can prospectively and retrospectively exacerbate the sense of loss. Similarly, for the patient who is dying from end-stage terminal illness, such suffering can purloin what time is remaining, and thus diminishes the capacity for meaningful reflection and relational closure with loved ones, and the life-lived, in general (4). 


\section{On Moral Obligations}

Clearly, a moral obligation exists to relieve pain and suffering at any point in the lifespan, and this obligation is heightened in those situations in which cure is impossible, and thus palliation remains the only viable alternative. In this way, it can be seen that pain management can be, and often is necessary, albeit not sufficient for rendering sound, palliative care. This bespeaks the need to view pain medicine and palliative care as conjoined within an over-arching interdisciplinarity that is focused upon the best interest(s) of the patient (in this context, taken most literally from the Latin patior as 'the one who suffers'. This appreciates that the multidimensionality of pain - as uniquely, and subjectively experienced in each person - determines the medical needs that must be provided $(5,6)$. The obligation to treat pain and suffering, while inherent to all of medicine, is by definition most fundamental to the profession of pain medicine and palliative care(1). In executing the act of profession- that is the public declaration of knowledge, skills and intention(s) - the pain and/or palliative care physician asserts that he/she will utilize the right types of knowledge, to guide the right clinical actions in the specific contexts of a particular patient's care (7).

But technically effective care must also be rendered in ways that uphold the moral affirmations of medicine, and while certain ethical (and legal) frameworks exist to guide the tenor, scope, and limits of the practice, the actual implementation of care remains reliant upon the agency of the physician (8). We have argued that this agency is not simply therapeutic, but is inherently moral given the vulnerability of the patient, the asymmetries of knowledge and power between physician and patient, and how these inequalities affect the nature of trust within the medical relationship (9). The complexity of pain and pain care is such that there may come a point in the treatment of a pain patient when a simple approach to management is no longer possible. The proverbial analgesic ladder can be rapidly overtaken when attempting palliative management of long-term or severe end-of-life pain. As Ballantyne notes in this issue, the use of systemic opioids can be wrought with difficulties including tolerance, dependence, ineffective analgesia, and deleterious side effects. We propose that interventional pain management may represent a viable option, both early in, and throughout , the care of longterm, and terminal pain patients. We believe that such techniques are especially useful for the treatment of the chronically and/or terminally ill who, because of their emphasis upon quality of life (in the former case, in an extended lifespan punctuated by intense pain, or in the latter within the limitations of end-of-life), require rapid, durably-effective analgesia with minimal side effects.

\section{Presumed Barriers to Interventional Pain Management in Palliative Care}

Interventional management techniques tend to be underutilized within palliative care - particularly palliative care that is provided within a paradigm of long-term (i.e. non-end-of-life) treatment. A number of long-held beliefs may contribute to this underutilization. Namely, it has been claimed that interventional pain management techniques are not worth the cost. Actually, when compared with long-term use of systemically administered primary and adjunctive/adjuvant analgesics, interventional techniques reveal a very favorable cost:benefit ratio (10). For example, the costs of a nerve block are more than justified when compared to those expended on attempts at systemically maintained analgesia, extrapolated across the duration of time needed to elicit a meaningful level of pain relief. Even if complete analgesia is not afforded by interventional techniques, the cost savings accrued by reducing the amount of opioids required and used might more than compensate for the initial expenditure(s) of interventional procedures.

Likewise, the notion that analgesia derived from interventional techniques is insufficiently durable to justify the cost(s) is a misconception given that analgesia from neurolytic blocks typically lasts for months (11). Similarly, it is believed that the need to repeat interventional pain management procedures may be unjustifiably burdensome to patients at end of life, or who require long-term palliative care. We counter this opinion with the historical fact that interventional pain management procedures were originally developed for use in the frail elderly - patients who were incapable of withstanding polypharmacologic or surgical interventions (12).

Last, it has been posed that the availability of interventional pain management specialists who are qualified to render treatment within the palliative care setting is limited, and therefore is a pragmatic barrier to the integrative use and effectiveness of interventional pain management in palliative care practice. However, the reality is that multispecialist interventional pain management practices can be found in 
almost all urban (and several suburban) areas in the United States. Moreover, the American Board of Pain Medicine mandates that palliative care and hospice experience be incorporated into the fellowship training of pain physicians, thereby directly facilitating the skill set(s) that are contributory to enhancing the integrative, collaborative potential of pain medicine and palliative care.

But this also speaks to the need to define interventional pain management as viable within palliative care, and strengthens the need to sustain interventional pain management as a discrete focus of practice. In other words, the interventional pain physician should not simply do interventional techniques, but should be a pain specialist. As such, the interventional pain physician remains first and foremost a physician, and the use of interventional techniques as a primary focus of practice - irrespective of setting - does not obviate the responsibilities inherent to the physician's practical and moral role(s) and responsibilites qua physician.

\section{Limitations and De-Limitations}

Thus, while the aforementioned presumed barriers have been overcome by research, professional training, and the growth of the field over time, there are additional factors that must be accommodated to allow a full, complete, and integrative collaboration between interventional pain medicine and palliative care. First, is that as physicians, interventional pain specialists must assume responsibility for the ongoing pharmacological management of their patients. To provide only interventional techniques, without accepting the task of meeting the post-interventional pharmacological needs of the pain patient (either singularly or in collaboration with other physicians) reduces the clinician to mere technician, refutes the act of profession, and in so doing is tantamount to patient abandonment. To be sure, long-term and endof-life pharmacological pain management can be difficult, but such is the nature of the practice as practically and ethically defined. Adroit pharmacological treatment requires the use of the most current information of pain and pain-related pathologies (e.g. substance abuse, psychopathology), pharmacological agents and their mechanisms, actions and effects, as well as the willingness and time to deal with the exigencies that arise within the care of such patients $(13,14)$. The papers provided by Ballantyne and Okon in this issue, as well as prior reviews by Manchikanti et al $(15,16)$ are noteworthy in providing significant information about pharmacological agents and techniques that can be employed in palliative pain care, and the pragmatic and ethical parameters of their use in such settings.

Second is the need for interventional pain physicians to recognize and understand the needs of the palliative care patient beyond those that determine and guide the placement of a nerve block. This speaks to the importance of recognizing not only which conditions are best suited for interventional management in the palliative care setting, but also what other (medically relevant) bio-psychosocial needs a particular patient may have, and how these needs may be served through an integrative, pluralist approach that conjoins other specialties (e.g. psychiatry, etc.). A patient's pain (type and history) should predict the need for early and/or ongoing interventional pain management, and such treatment should be considered whenever it is evidently burdensome for the patient to endure serial trials of systemic medications in which each failed trial may reduce the patient's hope, trust, and faith in the treatment process.

\section{Benefits and Potential of Interventional Pain Management in Palliative Care}

Clearly, there are many benefits of interventional pain management in the palliative care setting. First, with a single procedure, the patient can be afforded months of pain relief. This is important both for those patients who have progressive, durably lifelong pain (with its comorbid debility) and those who are approaching the end of life. Even in those situations in which the analgesia achieved by interventional procedures is incomplete, the relief that is obtained is frequently such that there is a significant reduction in opioid dose, thereby creating an opioid sparing effect, and increasing the response to opioids and/or non-opioid agents (see Ballantyne, and Okon, this issue). This decrease allows the dose of opioid or other systemically administered adjunctive analgesics to be tapered, diminishing potential side effects of these medications, as well as reducing associated costs.

Indeed, interventional pain management is often the best, or perhaps the only way to manage certain pain syndromes that are commonly encountered in the palliative care setting. While traditional teaching states that the failure of the primary pain management regimen indicates the need for interventional 
techniques, we disagree. Recent evidence supports the notion that early or even prophylactic use of diagnostic or therapeutic nerve blocks and/or intraspinal infusion therapy may save a patient a long, arduous, and often fruitless period of systemic medication titration $(10,15)$.

To reiterate, when cure is no longer possible, healing care must be maximized. In this way, the collaboration and conjoining of interventional pain management may well serve the scope and purpose(s) of palliative care. But this collaboration is not simply bipartisan. Palliative care can and often does involve the use of other medical techniques and sub-specialties - any or all of which may augment the success of in- terventional pain management. Forthcoming papers in Pain Physician will address these techniques and approaches, and it is in the spirit of such bridge building that we invite the readership to join the discourse, contribute information, and enhance such collaborative potential.

\section{Acknowledgements}

This work was supported, in part by funding from the Center for Clinical Bioethics and Division of Palliative Medicine, Georgetown University Medical Center (JG, GFG), and the Samueli Institute, Center for Brain, Mind, and Healing (JG).

\section{References}

1. Giordano J. Hospice, palliative care, and pain medicine: Meeting the obligations of non-abandonment and preserving the dignity of terminally-ill patients. Del Med J 2006; 78: 419-422.

2. Maricich Y, Giordano J. Pain, suffering and the ethics of pain medicine: Is a deontic foundation sufficient? Am J Pain Management 2007; 17: 130-138.

3. Leder D. The Absent Body. University of Chicago Press, Chicago, 1990.

4. Giordano J. Dignity, and pain medicine at the end of life. Prac Pain Management 2006; 6: 68-70.

5. Giordano J. Dolor, morbus, patiens: Maldynia, pain as the illness of suffering. Pain Practitioner, 2006; 16: 24-28.

6. Giordano J. Toward a core philosophy and virtue-based ethics of pain medicine. Pain Practitioner 2005; 15: 59-66.

7. Giordano J. On knowing: Domains of knowledge and intellectual virtue in practical pain management. Prac Pain Management 2006; 6: 65-67.
8. Giordano J. Technology, techniques, and tekne: On the ethical use of guidelines in the practice of interventional pain medicine. Pain Physician 2007; 10:1-5.

9. Giordano J. Pain, the patient and the physician: Philosophy and virtue ethics in pain medicine. In: Schatman M (ed.) Ethics of Chronic Pain Management, Informa NY 2007, p. 1-18.

10. Manchikanti L, Singh V, Kloth D, Slipman CW, Jasper JF, Trescot AM, Varley KG, Atluri KG, Giron C, Curran MJ, Rivera J, Baha AG, Bakhit CE, Reuter MW. Interventional techniques in the management of chronic pain. Pain Physician 2001; 4: 24-98.

11. Perello A, Ashford N, Dolin S. Coeliac plexus block using computed tomography guidance. Palliative Medicine 1999, 13: 419-425.

12. Ashburn MA, Staats PS. Management of chronic pain. Lancet 1999; 29; 353(9167):1865-1869.
13. Giordano J. The moral community of the clinical pain medicine encounter. Prac. Pain Management 2006; 6: 60-63

14. Manchikanti L, Giordano J, Boswell MV, Fellows B, Manchukonda R, Pampati V. Role of psychological factors as predictors of opioid abuse and illicit drug use in chronic pain patients. J Opioid Management 2007; 3:89-100.

15. Manchikanti L, Staats PS, Singh V, Schultz DM, Vilims BD, Jasper JF, Kloth DS, Trescot AM, Hansen HC, Falasca TD, Racz GB, Deer TR, Burton AW, Helm S, Lou L, Bakhit CE, Dunbar EE, Atluri SL, Calodney AK, Hassenbusch SJ, Feler CA. Evidence-based practice guidelines for interventional techniques in the management of chronic spinal pain. Pain Physician 2003; 6:3-81.

16. Manchikanti L, Pampati V, Damron KS, Fellows B, Barnhill RC, Beyer CD. Prevalence of opioid abuse in interventional pain medicine practice settings: a randomized clinical evaluation. Pain Physician 2001; 4:358-365. 